Behavioural Sciences | Professor Hadas Mandel

\title{
Gender inequality: occupational devaluation and pay gaps
}

The comparative research of long-term trends of gender inequality largely neglects structural mechanisms. As more women reach position of powrer, structural elements Despite the growing body of literature in this area the long-term effect of the changing gender compositio of occupations on their relative pay has been largely neglected. Hadas Mandel, an Associate Professor in the Department of Sociology University, has addressed this gap in the literature by exploring the negative effect of occupational feminisation on occupational pay in the US and the mechanisms underlying these trends.

he theoretical argument for understanding long-term tren of the association between feminisation and occupational pay rests on a distinction between two processes occurred in recent decades in the have occured in recent decades in the labour The first process, which relates to women as individuals, addresses the upward occupational mobility of wome meaning that women are incrementally entering higher rungs of the occupation hierarchy. The second process - which is conceptualized as a structural process - refers to the criteria for rewarding 列 occupational attainments of women over recent decades is evident in the way occupational feminisation affects the pay level of occupations. Atthough highlighted the negat reseach has between the percentage of women in occupations and their rewards, most of these studies have focused on the causal mechanisms of the process rather than on the dynamics over an extended period of time.

Prof Hadas Mandel sought to address trends in the effect of occupational

Structural mechanisms of gender/race inequality are not directed at any specific individual and thus are more ambiguous and more difficult to track empirically. is whether gender is one of the criteria and if so whether occupations a The literature documenting long -term trends in gender inequality has tended to focus heavily on the former - i.e. the upward occupational mobility of wome on the occupational ladder. The latter, i.e. the structural implications are largely overlook are inherently

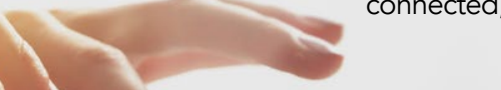

feminisation on occupational pay over the mechanisms underlying these trends. Using integrated data on individuals and occupations from the US Census (19602010) and the ACS surveys (2001-2015) her findings show, similarly to previous studies, that in recent decades, and especially from 1980 onwards, a growing number of women in the US have approached the head of the occupationa ladder (see the first figure below). This shift has been fuelled by women's growing educational attainments, which, together with the rising economic premium to education, have greatly contributed to the decline in gender wage gaps. Furthermore, based on these changes, the negative associs occupations and occupational pay levels declines over time (see model 1 in the ( This decline is most which US women witnessed, a seriod in mprovement in their occupational standing, and a period where occupations requiring higher education enjoyed a large wage premium. However, when examining the effect of ender composition of the occupation after accounting for women's higher education and for the level of education in occupations, the trend is reversed, the negative net effect of female percentage on occupational pay intensifies over time (see model 2 in the second figure below). These two opposite processes reflect the upward occupational mobsity of women, on the one hand, and its gendered

The major role education plays in explaining the divergent trends is twofold. The entry of women into and the growing economic reward to hig education and to occupations with high educational requirements, may both conceal the trend in the devaluation effect as they contribute to weakening the correlation between the percentage of women and pay across occupations over the course of time. Thus, the intensification of the devaluation effe is revealed only after controlling for education (at both the occupational and individual level), because the growing gducational level of women, and the growing rewards to education, are and thus conceal its intensification.

et's consider the example of industria engineers and electrical engineers. Both occupations demand high education. (more than $70 \%$ of incumbent workers in 2010 had an academic degree), and both enjoyed a wage premium during the period studied. However, while in both occupations the percentage of women in 1960 was negligible (2\% and $1 \%$, respectively), 50 years later only $10 \%$ of electrical engineers were women, compared to $19 \%$ - almost double - of industrial engineers. As both occupations enjoyed wage premiums, the devaluation precess of not be obsened because the process of feminization was not followed
Trends in female proportion in occupation by levels of average occupational pay.

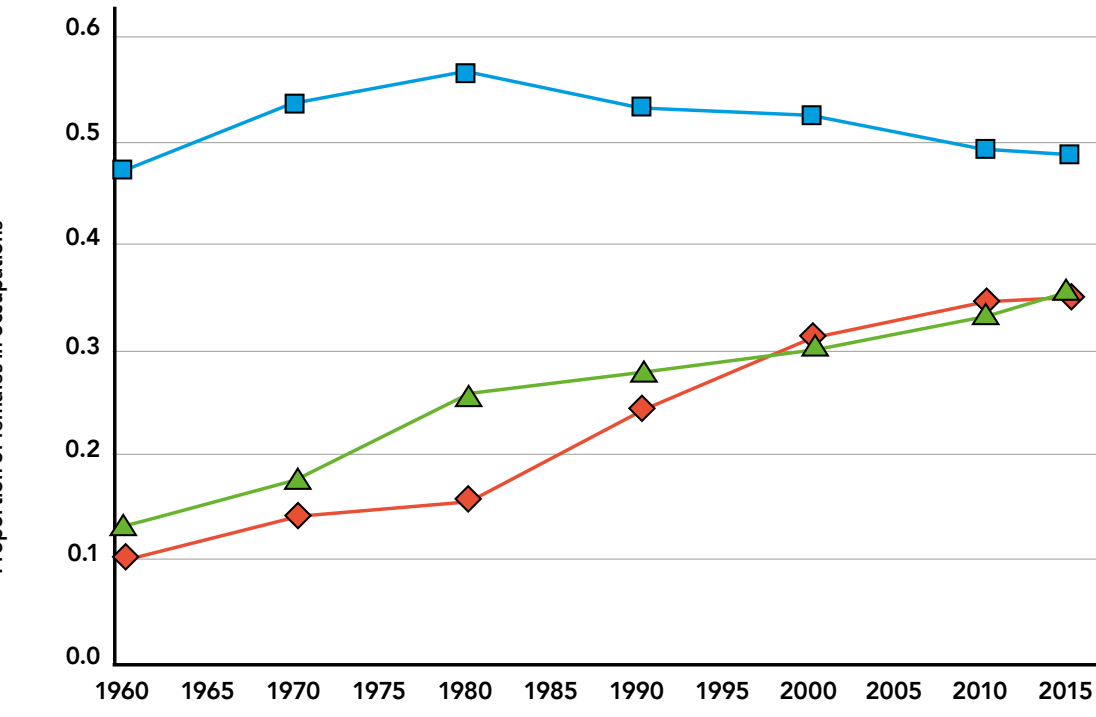

$\square-$ Low pay Tertile $\quad \triangle$ Mid pay Tertile $\checkmark$ - High pay Tertile

Trends in the effect of gender composition (\% female) on the average pay of occupations, before (Model 1)

and after (Models 2) accounting for education.

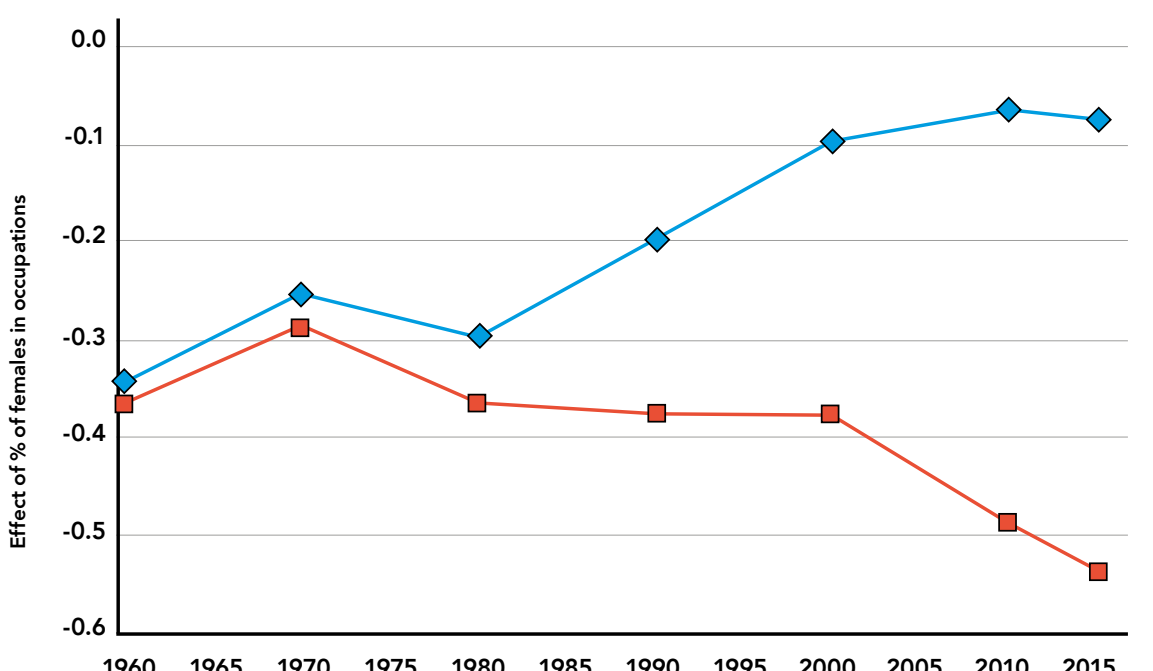

$\begin{array}{llllllllllll}1960 & 1965 & 1970 & 1975 & 1980 & 1985 & 1990 & 1995 & 2000 & 2005 & 2010 & 2015\end{array}$

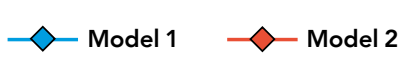

feminization is associated with a smaller wage premium relative to comparable highly educated occupations. Thus

provide concrete evidence that gender stratification operates differently at controlling for education is essential for revealing the devaluation process. Indeed, individual and occupational forms of we see that while electrical engineers gender in/equality and the divergent enjoyed a premium of $25 \%$ during the period studied, industrial engineers enjoyed a premium of less than $19 \%$

The findings demonstrate the interrelationship between two opposing gendered processes and trend of each are crucial for our

understanding of gender inequality in theory as well as in practice. This is directed at any specific individual and difficult to track enich decause structural mechanisms are not 
therefore that the importance of gender as a determinant of economic inequality less amobit and not sufficiently acknor

\section{GENDER AND RACIAL PAY GAPS}

\section{A different topic that Prof Mandel}

investigates deals with the intersection between race and gender in earnings inequality. Segregation and earnings disparities between blacks and whites observed at the turn of the $21^{1 s t}$ century those documented in the middle of the $20^{\text {th }}$ century. The rate of decline of the $20^{\text {th }}$ century. The rate of decline followil pay disparties was fairly rapid following the enactment of the Civi Rights Act but has slowed in recent decades. Despite the wide consensus declining, researc dispartes are on the soucs, causes, nond trajly agree of the decline or whether the trends are similar for both men and women. Although the literature on racial earnings disparities has grown, most studies on the topic focus on the male population.

To address this issue, Prof Mandel in collaboration with Moshe Semyonov, used IPUMS data between 1970 and 2010 to examine the trends and sources of the racial pay gap among men and women in the US labour force. Finding highlighted the significance of the intersection between gender and race. They found that gender differences in the racial pay gaps were so pronounced that

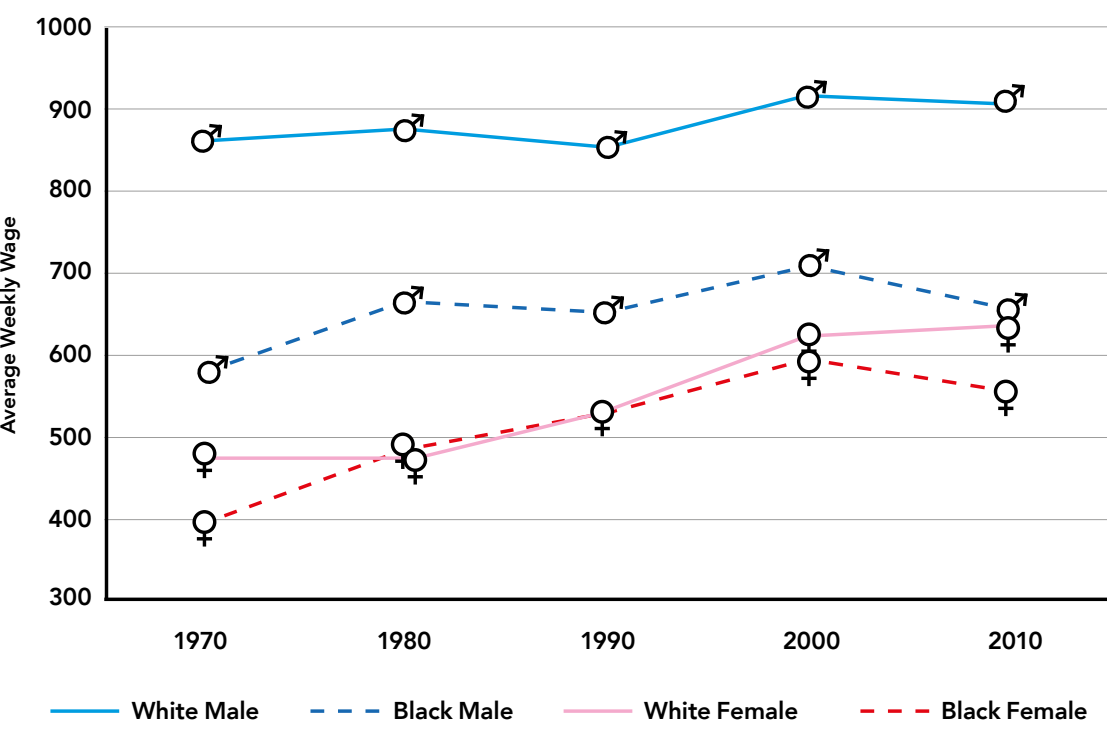

economic disadvantage in comparison with men. The 'racial advantage' of black stotistillycoss decades were women compared with black men should in the racial pay gap during the 2000 thus be understood within their overall was much smaller. This implies that gender disadvantage. the genders, the trend over time was very similar for both genders; racia gaps sharply declined between 1970 and 1980 and continued to decline at a slower rate until 2000. However, at the turn of the miliennium, the trend reversed for both gender groups. Given that earning inequality was found to be "more gendered than racialized" the "more gendis was much smaller. This implies that related to race, shifts in income distribution during the first decade of the millennium were more detrimenta to the earnings of blacks, particularly black men, than to those of whites.

Some evidence also implies an increase in market discrimination against blacks at the beginning of the new millennium During the 2000s, rewards to academic degree increased for whites more than for blacks and hus whites benefited on data for only first decade of the millennium were more by stagnation gender groups. detrimental to the earnings of blacks, $\quad \begin{aligned} & \text { in the processes } \\ & \text { of occupational }\end{aligned}$ Racial pay gaps

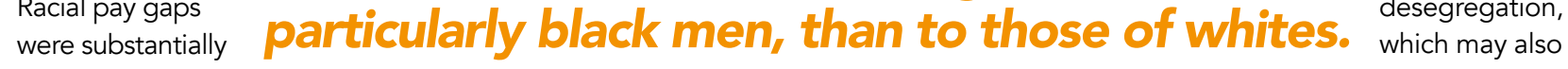
larger among

men than among women at all time points. Although this demonstrates the significance of the intersection of gender and race, the findings do not support a double disadvantage hypothesis. Instead, they show that black men, not black women, are the prime target of economic discrimination in the US labour market. However, the findings also show that earning inequality is more gendered than racialized. They a rise in economic discrimination against blacks. Although differen pay rewards of higher education stagnation in desegregation, are only implicit indicators for discrimination, the simultaneous changes in the two trends - i.e., the reversal of the trend among the two gender groups, coupled with our knowledge of government may point to growing periodincrease in overall inco the shap during the 2000s. The findings showed that, in the case of men (but not

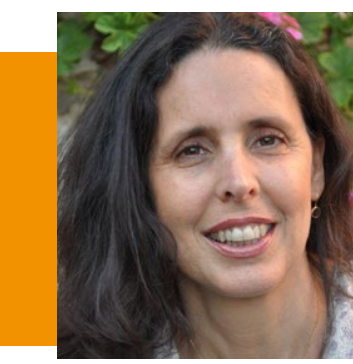

: hadasm@tauex.tau.ac.il T: +97236407922 W: http:///people.socsci.tau.ac.il/mu/hadasm/ W: https://scholar.google.co.il/

Despite these differences between for blacks and whites, as well as

\section{Research Objectives}

Professor Mandel's research addresses the analytical nd methodological distinctions between structural and individual aspects of gender inequality, underpinning and across societies.

\section{Detai}

The Department of Sociology and Anthropology Faculty of Social Science Naftali Building, Tel Aviv University. Ramat Aviv. Israel

Hadas Mandel is an Associate Professor in the Department of Sociology and Anthropology at Tel Aviv University. Her research focuses on the intersection between gender, class, race and the complex implications of weltare state policies on women's economic attainments. Since 2017, she is the Principal Investigator of the ERC-funded 'Structural vs. Individual' project addressing the analytical and methodological distinction between structural and individual aspects of gender inequality underpinn and across societies.

\section{Funding}

The European Research Council (ERC) under the Europea Union's Horizon 2020 research and innovation program

(Grant 641 Agreement No. 724351).

\section{Collaborators
- Amit Lazarus}

- Assaf Rotma

- Adi Moreno

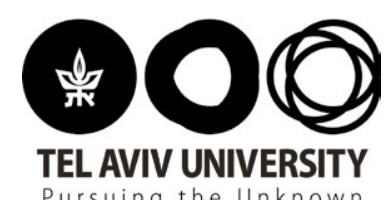

\section{References}

Mandel H. (2013). 'Up the Down Staircase: Women's Upward Mobility and the Wage Penalty for Occupational Feminization, 1970-2007'. Social Forces, 91 (4):1183-1207.

Mandel, H. (2016). 'The role of occupational attributes in gender earnings inequality, 1970-2010'. Social science research, 55,122-138.

Mandel, H., \& Semyonov, M. (2016). 'Going back in time? Gercial 1039-1068.

Mandel, H. (2018). 'A Second Look at the Process of Occupational Feminization and Pay Reduction in Occupations'. Demography, 55(2), 669-690.

\section{Personal Response}

\section{What is the focus of your future research in this area?}

II I I expect the dynamic of the structural vs. individual processes to vary between countries and also by class.
I thus seek to examine the processes in four representative countries - Sweden, Germany, Spain and the United States - that differ in many of the institutional aspects th affect gender inequality, including the provision of welfare, gender ideology, wage structure, and political economy
factors. Therefore, gender in/equality processes in these tactors. Therefore, gender in/equalty processes in the
countries are expected to take different forms in both structural and individual appearances. That said in all countries I expect gender in/equality processes to vary by class, and I thus seek to examine the processes after distinguishing between classes of workers. lexpect gender equality to be more pronounced and rapil for advantaged occupational mobility of skilled and educated women may expose highly rewarded occupations to devaluation and pay reduction more than others. 